University of Wollongong

Research Online

Faculty of Commerce - Papers (Archive)

Faculty of Business and Law

$1-1-2008$

\title{
Enhancing occupational health and safety in young workers: the role of social marketing
}

Anne M. Lavack

University of Regina

Sherry Magnuson

University of Regina

Sameer Deshpande

University of Lethbridge

Debra Z. Basil

University of Lethbridge

Michael D. Basil

University of Lethbridge, mbasil@uow.edu.au

See next page for additional authors

Follow this and additional works at: https://ro.uow.edu.au/commpapers

Part of the Business Commons, and the Social and Behavioral Sciences Commons

\section{Recommended Citation}

Lavack, Anne M.; Magnuson, Sherry; Deshpande, Sameer; Basil, Debra Z.; Basil, Michael D.; and Mintz, James H.: Enhancing occupational health and safety in young workers: the role of social marketing 2008, 193-204.

https://ro.uow.edu.au/commpapers/1302

Research Online is the open access institutional repository for the University of Wollongong. For further information contact the UOW Library: research-pubs@uow.edu.au 


\section{Enhancing occupational health and safety in young workers: the role of social marketing}

\section{Abstract}

- Young workers (age 15-24) suffer work-related injury at a much higher rate than older workers, yet research on the role and effectiveness of social marketing to influence and improve workplace safety is limited.

- A review of the relevant literature reveals that significant gaps exist in terms of effectively using social marketing to reduce young worker injury rates.

- A comprehensive, multi-faceted social marketing approach is required to address young worker safety.

- Directing more attention toward the practice of social marketing can enhance the effectiveness of campaigns to reduce workplace injurie.

\section{Keywords}

Enhancing, occupational, health, safety, young, workers, role, social, marketing

\section{Disciplines}

Business | Social and Behavioral Sciences

\section{Publication Details}

Lavack, A. M., Magnuson, S., Deshpande, S., Basil, D. Z., Basil, M. D. \& Mintz, J. H. (2008). Enhancing occupational health and safety in young workers: the role of social marketing. International Journal of Nonprofit and Voluntary Sector Marketing, 13 (3), 193-204.

\section{Authors}

Anne M. Lavack, Sherry Magnuson, Sameer Deshpande, Debra Z. Basil, Michael D. Basil, and James H. Mintz 


\title{
Enhancing occupational health and safety in young workers: the role of social marketing
}

\author{
Anne M. Lavack ${ }^{1 *}$, Sherry L. Magnuson ${ }^{2 \dagger}$, Sameer Deshpande ${ }^{3 *}$, \\ Debra Z. Basil ${ }^{3 \$}$, Michael D. Basil ${ }^{36}$ and James (Jim) H. Mintz ${ }^{4}$ \\ 'Faculty of Business Administration, University of Regina, Canada \\ ${ }^{2}$ Graduate School of Public Policy, University of Regina, Canada \\ 'Facutty' of Management, University of lethbridge, Canada

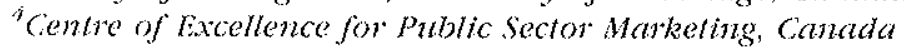

- Young workers (age 15-24) suffer work-related injury at a much bigher rate than older. workers, yet research on the role and effectiveness of social marketing to influence and improve workplace safety is limited.

- A review of the relevant hiterature reveals that significant gaps exist in terms of effectively' using social marketing to reduce young worker injury rates.

- A comprehensive, multi-faceted social marketing approach is required to address young worker safety.

- Directing more attention toward the practice of social marketing can enhance the effectiveness of campaigns to reduce workplace injuries.

Copyright 2007 John Wiley \& Sons, Ltd.

\section{Introduction}

Social marketing is just beginning to be embraced in the area of occupational health and safety (OHS). While the literature on OHS includes extensive coverage of general work injury rates and trends, workplace safety

\footnotetext{
"Correspondence to: Anne M. lavack, Professor \& Associate Dean, Faculty of liasiness Administration, University of Regina, 3737 Wascana Parkway, Regina, SK S4S 0A2, Canada.

E-mail: Annc.Lávack@ureginaca

irracluate Student.

Assistant Professor of Marketing

Associate Professor.

professor.

Director.
}

cultures and climates, and new and emerging OHS strategies, there is relatively little in the literature about the role of social marketing in reducing workplace injury and the effectiveness of social marketing initiatives to address and reduce occupational injuries. The literature on the use and effectiveness of social marketing to enhance OHs for young workers (age 15-24), who suffer work-related injury at a much higher rate than older workers, is similarly limited in scope. Therefore, the goal of this paper is to examine the role of social marketing in inproving workplace safety for young workers, and provide guidance for implementing such social marketing campaigns. 


\section{Prevalence of work-related injuries}

In the United States, there are 13 million nonfatal work-related injuries each year. The total number of annual occupational deaths, injuries, and illnesses in the U.S. translates into 2.8 million lost workdays (Lyon and Hollcroft. 2005). Total annual direct and indirect costs of workplace injuries are estimated to be between $\$ 110$ and $\$ 120$ billion (Kaminski, 2001; Ayers and Kleiner, 2002; Wallace and Vodanovich, 2003). Direct costs include the cost of paying for treatment of injuries and providing compensation to injured workers. Indirect costs include lost years of productivity due to injury or fatality, usually measured by lost future wages.

In Canada, a country with one-tenth of the population of the United States, the statistics are similarly bleak. An average of over 500000 occupational illnesses and injuries were reported yearly throughout the 1990 s, translating into a work-related illness or injury in 1 out of every 18 workers (Breslin and Smith, 2005). The direct cost of each workplace injury in Canada is estimated at $\$ 6000$, while the direct cost of each workplace fatality is in the range of $\$ 492000$ (Barling et al., 2003).

Young workers suffer work-related injury at a much higher rate than older workers (IWH, $2006 \mathrm{a}$; Schulte et al., 2005). In particular, those between 15 and 24 years of age have an elevated risk of sustaining a work injury (Loughlin and Barling, 2001; Breslin and Smith, 2005; IWH, 2006b). Fifty per cent of the accidents involving this age group occur cluring the first 6 months on the job (Beharie, 2003).

The U.S. National Institute of Occupational Safety and Health (NIOSH) estimates that 200000 workplace injuries occur each year among youth (under age 19) in the United States (Loughlin and Frone, 2004), while approximately 60000 young workers (age 15-24) have lost-time injuries each year in Canada. The total annual cost of occupational injuries among teens (age 15-19) in the U.S., including both direct and indirect costs, is estimated to be $\$ 5$ billion dollars (Miller and Waehrer, 1998; Schulte et al., 2005).

\section{Understanding the young worker target group}

Surveys reveal that young workers do not rank safety as high in priority, nor do they place workplace injury top of mind (Beharie, 2003). A 2003 national survey of 15 to 24 -year-old Canadian workers revealed that few recalled seeing OHS information during the past year, and only $12 \%$ were concerned about workplace dangers and injuries (Freiman, 2003). Yet concerns about workplace safety do exist among young workers, and become more evident when youth are questioned within focus groups or in-depth interviews. For example, research conducted with teens in the retail sector in North Carolina revealed workplace concerns about 'unsafe environments, fear of assault, being rushed, feeling powerless, and receiving inadequate training from managers insensitive to safety issues' (Zakocs et al., 1998: 345).

Personal factors play a key role in worker safety. Workers more at risk of workplace injury are those who are younger, male, in poor emotional or physical health, or who use illicit substances (Loughlin and lrone, 2004). lactors related to physical and psychological development also contribute to young worker injuries (Castillo, 1999). Young workers may lack the emotional and physical maturity necessary for certain tasks (linker et al., 2005: IWH, 2006a). Cognitive development is typically not com plete until young people are well into their twenties (Brown, 2003). While younger males may appear to be physically well developed they often lack the full adult decision-making and cognitive functioning necessary to make wise work-safety judgments (Beharie, 2003). Young people's organs and musculoskeletal systems are also undergoing rapid growth, creating greater likelibood that they will be harmed through exposure to hazardous substances or develop cumulative trauma disorders (Linker et al, 2005). 
Young people have higher risk thresholds than adults, are mrealistic about their own mortality, and view themselves as invulnerable and immortal (Loughlin and Frone, 2004; Smith, 2004). 'This can cause them to abandon standard company procedures in favor of taking short-cuts, accepting risks, and ignoring hazards (Dehaas, 1996; Beharie, 2003). Young workers may not be aware of workplace hazards or they may assess them differently, leading to umpreparedness and risky approaches that increase injury rates (Loughlin and frone, 2004; Smith, 2004; Budworth, $2006)$.

Unsale work behaviors among youth can stem from many motivations, including a desire to earn workplace rewards for pro ductivity or gain the approval of supervisors and peers (Loughlin and Frone, 2004). Young workers are casily influenced to follow the lead of others, especially other youth showing at-risk behavior. Peer pressure and a desire to 'fit in' can sometimes result in unsafe work practices, particularly when the social and workplace climate is one where risk-taking is admired (Beharie, 2003). According to Brown (2003: 6), Youthful exuberance and navety combines with a desire to impress and a fear of questioning authority, often with tragic consequences".

Young workers are also more at risk because of their lack of work experience (Castillo, 1999; Loughlin and Barling, 2001; Schulte et al., 2005). They are usually less skilled, and yet may overestimate their own skills and abilities while underestimating their risk of injury relative to their peers (Loughlin and Frone, 2004). Young people new to a workplace may avoid asking questions in order to avoid looking foolish, incompetent, of unknowledgeable (Beharie, 2003; Brown, 2003; Janieson, 2005). They often lack a sense of empowerment or self-confidence, as well as communication and social skills, making it difficult to question the safety of a job, convey their concerns to their supervisors, challenge those who might expect them to perform unsafe acts, report accidents, or put into practice what they learn in training programs (Stelmakowich, 2002; Smith, 2004; Linker et al., 2005; Schulte et al., 2005).

Young workers are frequently involved in low-paid temporary, seasonal, or part-time jobs with variable work schedules. As a result, they must respond to changing employer demands, making them less able to gain site-specific knowledge and skills (Castillo, 1999; loughlin and Frone, 2004; Breslin and Smith, 2005). This part-time or temporary approach to work can lead to a weaker safety culture and the phenomenon of being 'new on the job' for a greater length of time, in turn increasing the risk of injury (Breslin and Smith, 2005; IWH, 2006a). Younger workers often do not know their legal rights, do not know which work tasks are prohibited by labor laws, and are not familiar with safe-operating procedures and work requirements for certain tasks (Linker et al., 2005).

This review of the young worker target group has demonstrated that young workers have a unicue profile compared to older workers. Given the rates of worker injury among young workers, it is worth investing a significant amount of time, effort, and money to improve workplace safety for this target group. Current approaches focusing on education and training have had some success in improving workplace safety. However, social marketing is a more comprehensive approach that has not been tried to any significant extent within the OHS context, yet the existence of a clearly defined market of young workers merits a targeted social marketing approach. Following is an explanation of the main tenets of social marketing and how these concepts could be used to improve workplace safety.

\section{Employing social marketing to promote workplace safety}

Social marketing is defined as the use of marketing principles and techniques to influence a target audience to voluntarily accept, reject, modify, or abandon a behaviot for the benefit of individuals, groups, or society as a 
whole' (Kotler et al., 2002:5). Social marketing attempts to change behavior by facilitating exchange, conducting research (formative, process, and evaluation), segmenting and targeting, analyzing the target audience (attitudes, noms, values, lifestyle, etc.), examining the benefits and barriers the target audience seeks from the current behavior and new behavior, and developing strategy (4 Ps) for both upstream and downstream audiences.

In social marketing theory, an exchange takes place (Andreasen and Kotler, 2002) between the target (i.e., the worker) and the marketer (i.e., the employer or a workplace safety organization). This exchange requires that the worker be persuaded to give up something in order to gain somerhing. What is given up are the benefits of the unsafe behaviors or habits that the worker has previously engaged in; what is gained by the worker is an enhanced level of safety and a greater likelihood that he/she will not be injured. A social marketing campaign is also characterized by the use of marketing research to guide campaign development (Kotler et al., 2002).

Segmenting and targeting the market helps to identify the most receptive audiences along with their key concerns and issues, and then allocates campaign resources to these segments (Deshpande and Basil, 2006). In general, narrowly defined target audiences (e.g., young workers age 15-24) are preferred since they tend to be more homogeneous in their demographic and psychographic charac teristics. This approach facilitates the creation of social marketing campaigns that are targeted toward a specific group, and specially designed campaigns tend to be received more favorably than generic campatigns (e.g., Marshall and Brown, 2003). It is equally important to assure that the correct target group receives the message, as targeting the wrong group can be detrimental (Jones and Owen, 2006). Social marketing involves analysis of the target market, including attitudes, norms, values, and lifestyle, and the benefits and barriers that the target audience seeks from the current behavior and new behavior.

\section{Ps of social marketing}

Comprehensive social marketing campaigns generally develop a strategy by manipulating several of marketing's 4 Ps (product, place, price, promotion; sec Figure 1 ). When planning an OHS social marketing campaign, promotion is often the first of the 4 Ps to be manipulated because a variety of communication materials can be readily developed to persuade or remind workers to adopt safer work practices. Workers are more likely to become aware of the need for safety when safety nessages are delivered at both conventional (work) and unconventional (nonwork) locations. Having a variety of safety messages throughout work locations reinforces the jolea that the workplace embraces a safety culture which encourages safe work practices and behaviors. Nevertheless, it is important to consider ways that all 4 Ps of price, product, place, and promotion are managed in the context of an OHS campaign.

The 'price' the target atudience pays for following a particular safety practice might be a reduction in the speed with which a job can be cone. Part of the price may be looking 'unmanly' by using a particular safety precaut tion. The price could be financial, if the worker must buy expensive work boots, for example, rather than wearing runners. The social marketer's task is to demonstuate the value of safety, so that the 'price' paid seems worth the safety that is being gained.

'The basic 'product' of safety can be positioned as being inextricably linked with enjoyment of life, given that unsafe worlsplace behavior can have drastic conseguences on future health and wellness, and hence on enjoyment of life. 'The 'product' element of the social marketing mix can be divided into the actual, core, and atumented product. Actual product is the desired behavior being promoted (e.g., wear gloves while operating a machine). Core product is the end benefit of carrying out the desired behavior (e.g., higher cuality of life, or a better guarantee of future wages). Augmented product includes tangible products (e.g., gloves, helmets, back braces, 


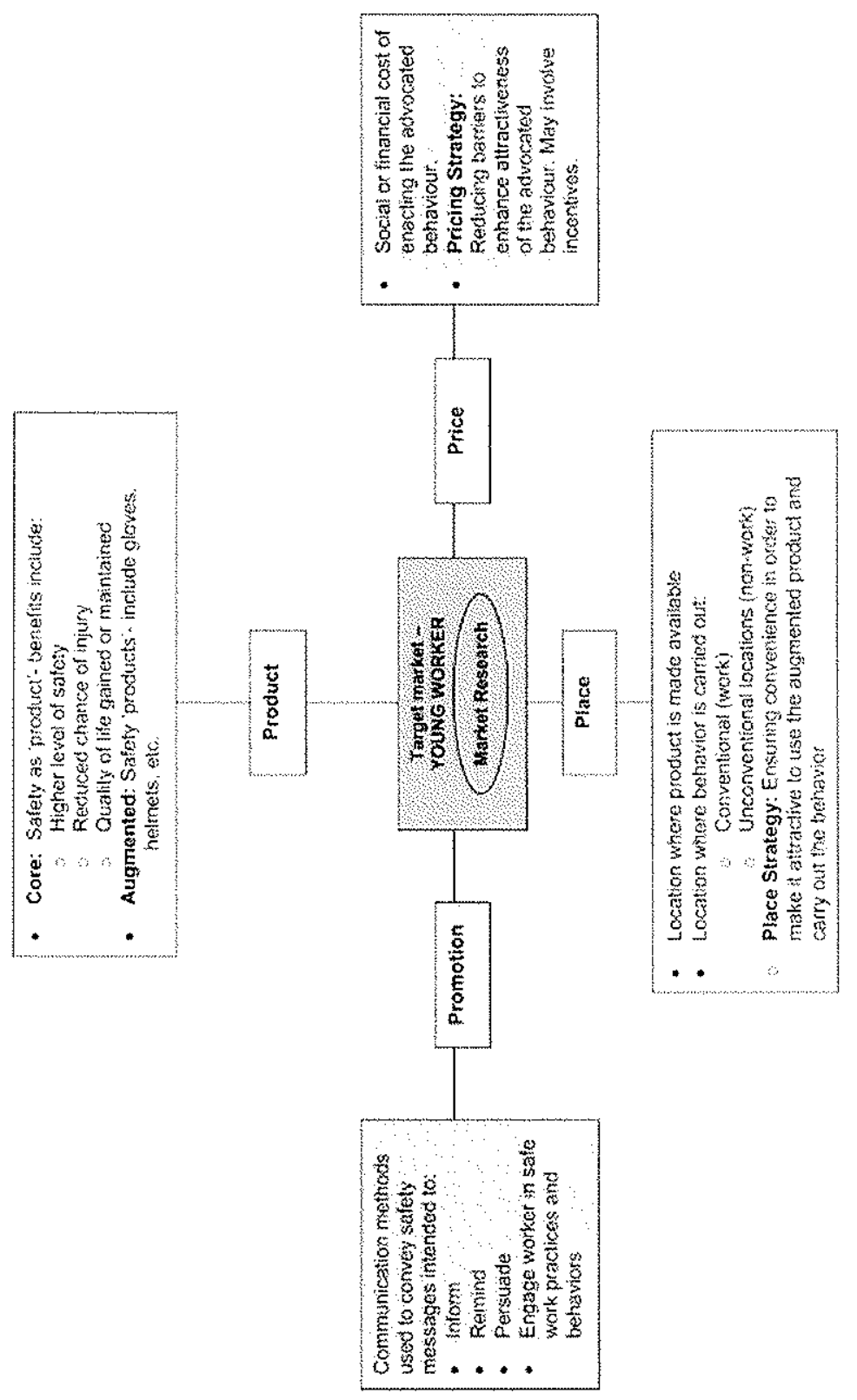

总) 
goggles, etc.) or intangible services (e.g., training workshops on safety).

"Place" is the location where the product is made available and where safety behavior can be carried out. If use of a particular work-safety product is being advocated, such as rubber gloves or goggles, then locating that product conveniently for worker use is a crucial element of "place'.

\section{Evaluating social marketing applied to oHS}

Only a handful of studies have evaluated social marketing efforts in OHS, and the research suggests that these social marketing efforts have generally been successful. In one luropean study, worker injuries were reduced $25 \%$ as a result of a multi-faceted information campaign targeted at improving safety attitudes of workers involved in a major construction project. 'The campaign information reached many contractors and employees jointly working on a complex but short-term project, thus having the potential longer-term effect of promoting a higher level of safety in the construction and building industry (Spangenberg et al., 2002).

A study of the Fort McMurray Demonstration Project in Social Marketing emphasized com. munity empowerment (Guidotti et al., 2000). Interventions included within the safety program included a cable 'TV media campaign. school activities, a community safety audit, and media appearances by a dinosaur mascot (Saferysaurus) which provided the program with a visual identity. This project illustrated how community and worksite promotion of safety and health can be mutually reinforcing, and that the worksite social support structure can strongly influence behavioral change.

The comprehensive use of social marketing rools was ilhustrated in a case study of an Australian company's long-term safety program. 'This program successfully employed a variety of social marketing tools to 'promote management commitment and employment involvement in OHS by fostering participation and co-operation at all levels in the decisionmaking process' (Vecchio-sadus and Griffiths, 2004: 617). Results of the study show that the organization's safety culture can be enhanced by promoting and publicizing both manage. ment commitment to OHS and employee participation in OHS.

Involving workers in developing work-safety communication materials represents an area that has shown promising results. One study examined Hispanic construction workers who were actively involved in designing, developing, and validating the various stages of a safety education and training project targeted at their group. Cultural and language differences within ethnic groups created challenges in using education and training to promote OXS to these workers, so involving workers in the development of social marketing programs significantly improves the efficacy of the program (Brunctte, 2005).

Building on the idea of worker involvement in developing campaign materials, one study examined the Washington state program entitled Health and safety Awareness for Working 'leens, and demonstated that an educational intervention program using interactive exercises developed and tested with teens was able to successfully help young workers develop the critical thinking skills necessary for protecting themselves in the workplace. Evaluations showed that student knowledge increased after exposure to the safety curriculum. Using teens to help develop programs aimed at their own target group helped to ensure the materials were relevant and well targeted (linker et al, 2005). This research shows that teens can experience lifelong benefits from carly exposure to schoolbased OHS education programs that are informed and supported by community partiners.

While these examples have primarily focused on promotion rather than all of the $4 \mathrm{Ps}$, they provide encouragement that social marketing has the potential to offer positive benefits in $\mathrm{OHS}$ situations. However, because social marketing has not been widely used in OHS, its full potential has not yet been realized. 


\section{Campaigns to promote safety among young workers}

While most worker safety campaigns do not employ all of the 4 P's of social marketing, many do focus on either 'promotion' or 'place'. This section uses examples from existing campaigns to examine how some facets of social marketing are being incorporated into workplace safety campaigns targeted at youth.

Getting the safety message across to young workers through social marketing campaigns can be challenging because of their lower levels of fear (Weadock, 2003). Young workers must be addressed in age and awarenessappropriate ways, taking into account their lack of perceived danger and sense of vulnerability (Linker et al., 2005). In order to reinforce a message or program, a combination of different communication techniques is needed in order to accommodate different learning styles.

\section{Safety campaigns}

In an attempt to reduce young worker injury rates, many organizations offer education programs, web sites and social marketing campaigns focusing on educating and protecting young workers (IWH, 2003). The Intenet is an increasingly useful tool to reach young people with safety messages, allowing them more control over gathering and absorbing the information (linker et al., 2005). For example, the U.S. federal government has launched the FedNet website with the goal of getting information to youth on work activities, and to change their behaviors so that they will have safe and healthy work experiences (Professional Safety, 2005). The Canadian federal government employs a national website to link OHS resources to young and new workers (CANOSH, 2006). Passport to Safety, supported by the Ontario Workplace Safety Insurance Board (WSIB), offers young workers a free online health and safety course (Jamieson, 2005).

Several provinces, provincial organizations, and workers' compensation programs have launched programs to ensure young people are aware of workplace hazards. This includes efforts to reduce the personal perceptions of immortality or invincibility held by many young workers (Young, 1998: 26). For example, shocking graphic images were used by the Workers Compensation Board of Nova Scotia (WCB of NS) in its 2005 young worker social marketing campaign. The campaign incorporated images such as a severed hand or a bloody eyeball on a silver plate, with an accompanying price tag to emphasize that body parts are more important than hourly wages (WCB of NS, 2005). Similarly, the Workers Compensation Board of British Columbia (WCB of BC) adopted a similar campaign during 2006 that uses graphic website images of severed body parts to get young workers' attention, along with a free television contest that creates an incentive for youth to explore the website (WCB of $\mathrm{BC}$, 2006). However, some have criticized this graphic approach as being attention-grabbing and devoid of personal connection to young people (Beharie, 2005).

Personal real-life stories from victims and/or their families are considered an effective method for causing a young person to connect to the real and long-tem consequences of workplace tragedies (Van Den Broek, 2004; Beharie, 2005). The main purpose of the 2002 WSIB young worker campaign was to change attitudes away from the concept of invinci. bility. This campaign, which included radio advertisements and posters in subways with tear-off pads listing workers' rights, focused on real stories of how people have been impacted by workplace illness and accidents. Market research indicated that the campaign raised awareness levels among both youth and employers (Tomlinson, 2002).

Recent research conducted by the WCB of BC shows that peertopece communication elicits the best response from young people (Beharie, 2003). Drama plays have been developed in British Columbia high schools, allowing students to come up with their own ways to spread OHS messages to their peers (Van Den Broek, 2004). The Ontario-based 
Industrial Accident Prevention Association (IAPA), through its Young Workers Awareness Program (YWAP), engages injured young workers to share their stories in the classroom in order to make occupational hazards real, while emphasizing positive reinforcement, choices, rights, and doing things differently (Young, 1998).

One U.S. safety marketing campaign targeted at under-30 male construction workers and titled 'Sexy Safety Stuffers' combined eye-catching flyers with brief safety messages in worker's pay cheques. This ongoing campaign used messages that were fresh and continually changing in order to hold the target group's attention (Cable, 2005).

\section{Community-based approaches}

Social marketing can also employ communitybased approaches to promote desirable behaviors (Deshpande and Basil, 2006). Young worker injury prevention can benefir from community-based approaches that combine regulations, improved work-design, and safe and healthy work environments (Castillo, 1999). A more holistic approach to training for young workers involves a variety of community sectors beyond the employer (Van Den Broek, 2004: 42).

There are several examples of community. basect approaches to young worker safety in North America. Three NIOSH-funded projects in the U.S and at preventing youth workplace injuries involved the development and delivery of high school curricula, materials for young employees and their parents, and strategies to provide effective training for young workers (Schulte of al., 2005). NIOSH also recently published recommendations for employers, parents, educators, and adolescents about the workplace, with the messige that 'entrenched community involvement is the only way to change behaviors and attitudes about safety...this standard has to be maintained by everyone, even parents' (Young, 1998: 30).

Groups that can and should be involved in community-based approaches to young worker safety include industry and labor groups, OHS practitioners, policy makers, standards-setting groups, equipment manufacturers, parents, educators, researchers, health care providers, and community groups (Castillo, 1999; Linker ef al., 2005). Young people's work attitudes, beliefs, and values are affected by their families (Loughlin and Barling, 2001 ), and parents of young workers can positively influence their own children and act as role models for young coworkers (IWH, 2003). Health care providers need to become more educated about OHS, more involved in documenting injuries, and promote the importance of safety equipment and practices to the community (Dunn et al., 1998).

\section{Upstream campaigns as an element of social marketing}

The literature on recommended youth-specific workplace saffety interventions is limited. However, there is an encouraging new emphasis on developing a safety culture and the adoption of behavior-based safety approaches, with a focus on 'upstream' (proactive) versus 'downstream' (reactive) approaches to safety management (Donovan and Henley, 2003; Andreasen, 2006). Proactive upstrean approaches take a longerterm view of worker safety by creating structural changes in the workplace that ensure work is made safer through better equipment, procedures, and policies.

Upstream approaches target employers wather than workers to take responsibility Employers must be encouraged to make structural changes to provicle and promote a safe and healthy work environment, ensure that machinery, work processes, and environments are appropriately modified and controls are in place, and provide traning in hazards and safe workplace practices (Castillo, 1999; Breslin and Smith, 2005; Schulte et al., 2005).

Employers need to recognize that young workers are entering the workforce at a time in their lives when they are experiencing significant developmental changes from a 
psychological, social, and career point of view (Loughlin and Frone, 2004). Social perceptions about supervisors, coworkers, and parents serve as important factors underlying youths' risk-taking orientation at work (Westaby and Lowe, 2005). In adition to making structural upstream changes to enhance safety, employers need to reinforce safety and health practices and provide rewards for safe benaviors and activities.

In order to keep young workers safe, employers need to introduce them to the workplace in a careful, organized way, focusing on designing jobs and tasks for new employees, training, and daytorday supervision (Dehatas, 1996). Young workers are more prone to a workplace injury in the first month of employment; therefore employers should invest in youth programs and place special focus on the early employment stages (IWH, 2003). Special workplace interventions are especially needed for young male workers because of their increased levels of risk-aking (Loughlin and Frone, 2004).

Young workers' jobs should have developmentally appropriate task variety and responsibility in orter to reduce risk of injury caused by job boredom and inatention. Compared to older workers, young workers are more likely to take short-cuts or experiment with different work methods that may present safety concerns. For this reason, employers need to spend more time communicating safety information to young workers, as well as doublechecking and supervising their work (Dehatas, 1996). 'Tailoring workloads to their cognitive and physical capacities will help reduce workplace injuries among young workers (Loughlin and Frone, 2004).

Employers should recognize that young workers need to be trained, instructed, and supervised differently than adul workers (Dehaas, 1996; Castillo, 1999; Beharie, 2003). Intervention strategies for hazards should be age-specific, and skill-based training should emphasize individual limitations (Loughlin and Frone, 2004 ). The more training and experi ence young people have, the less likely they are to get injured at work (Ross, 2003; Breslin and
Smith, 2005). Young workers have identifed enhanced supervision, reduced physical hazards, and increased young worker responsibility as important factors to improve workplace safety (Zakocs et al., 1998).

Young workers also have to be notivated differently from older workers. Employers should create workplace environments where young people feel valued and are comfortable and encouraged to be more assertive and ask questions (Zakocs ef al., 1998; 'Tomlinson, 2002; Brown, 2003). Communication skills and assertiveness education should be incorporated into existing safety training. Managers also need to be willing to communicate and interact in ways that will not threaten or intimidate young workers who voice their concerns or question authority ('akocs et al. 1998).

The level of company commitment to safety is a contributing factor to young worker safety (Castillo, 1999). Strong and positive safety climates have a beneficial effect on injury-related outcomes (Loughlin and Frone, 2004). Safety climate emphasizes the perceptions and attitudes held by employees regarding the importance of safety in their organization and the types of safety and health behaviors that are supported, expected, and rewarded at work (Westaby and lee, 2003; Dejoy et al., 2004). Safety climate has been shown to be an antecedent of safery performance, and the relationship between the two may be mediated by such things as safety motivation, safety knowledge, and skill of the individual, which in turn affect safety outcomes in an organization (Griffin and Neal, $2000)$.

Some North American companies have started to make adjustments to address young worker injury statistics. Honeywell Systems, a Canadian company based in Ontario, uses a multifaceted approach to reach their young workers, inchuding personal stories about lifertlering young worker accidents as well as greater parental involvement (Van Den Broek, 200 S). leckor Industries, a construction contracting company, has adopted an approach with young employecs under 25 years of age at its North American 
worksites that emphasizes mentoring and constant supervision during the adjustment stage of early employment (Beharie, 2003). Upstream approaches play a key role in successful social marketing campaigns, and are essential in extending the effectiveness of downstream approaches.

\section{Conclusion}

The research on workplace safery suggests a number of best practices. It seems clear that comprehensive social marketing programs sustained over time are more effective at facilitating behavioral change. Programs that incorporate personal real-ife stories may better help young workers to comprehend the need for workplace safety. Peer-to-peer communication and peer involvement in developing communication materials are two methods that ensure the relevance of workplace safety campaigns, Community-based approaches provide a multi-faceted approach to workplace safety wherein the community broadly supports employer safety efforts. Upstream efforts create proactive approaches to worker safety by making work safer through structural change that introduces safer equipment, better procectures, and stronger policies. Finally, recognizing the unique chanacteristics of young workers should result in training, supervision, and motivation that is uniquely designed to meet their needs.

Overall, OHS campaigns have displayed success in understanding young worker atti tudes, values, and lifestyles and in using that knowledge to target and segment this market. However, up to this point, there has been less focus on facilitating behaviotal change and employing product strategies. There appears to be some focus on formative research, but less on outcome evaluation. 'The emphasis has been more on a downstream rather than apstream approach.

lhere is limited research examining social marketing campaigns on the topic of workplace safery, even when the definition of social marketing is extended to include more limited campaigns that focus primarily on workplace safety communication of education where emphasis is placed on promotion of behavior without employing product and price strat egies. Only a handful of studies specifically evaluate educational materials or communi cation campaigns to improve workplace safety, but fewer than half mention 'social marketing or refer to the full range of elements that would nomally comprise a social marketing campaign, or measure the effectiveness of workplace safety campaigns.

This handful of studies that evaluate the use of social marketing technicues to enhance workplace safety highlight the fact that innovative approaches and methods are needed to get the OHS message across in ways that will positively influence workplace behavior and practices. There is little doubt that social marketing can be an important ingredient in the worker safety recipe, and more research is required to determine the most effective role that social matketing can play. Future research should focus on evaluating workplace safety social marketing campaigns, in order to provide insight into which elements of social matketing are most likely to facilitate behaviowal change.

\section{References}

Andreasen AR. 2006. Soctal Matketing in the 2Ist Century. Sage: Newbury Park, CA.

Andreasen A, Kotler P. 2002. Strategic Manketing for Nomprofit Organizations, Gth edn. Prentice Hall, Upper Saddle River, NJ

Ayers PA, Kleines BH. 2002. New dexelopments concerning managing human factors for safety. Manazerial law 44(1/2): 112-120.

Barling J, Jverson RD, Kelloway EK, 2003. Highquality work, job satisfaction, and occupational injuries. foumal of Applied Psycbology 88(2): $276-283$.

Beharie N. 2003. New kid on the block. OHES Canada 19(4): $30-38$.

Beharic N. 2005. Get real. OIFs Canada 21(5): 4. Breslin C, Smith P. 2005. Age-telated differences in work injurics: a multivariate, population-based 
study. American fournal of Malustrial Hedicine 48: $50-56$.

Brown D. 2003. Many young workers die before first payday. Canadian HR Reporter 16(9): 6 .

Brunette MJ. 2005. Development of educational and training materials on safety and health: taxgeting hispanic workers in the construction industry. Family and Community lleallh 28(3): $253-266$.

Budworth N. 2006. Safeguarding the next generation. The Safely \& llealth Practitioner 24(2): 23.

Cable J. 2005. Gencration Y safety: the challenges of reaching the under 30 worker. Occupational Harards 67(11): 21-24. 54 .

Canada's National Occupational Health and Safety Website (CANOSH). 2006. http://www. canoshweb,org/en/young wotkershtml [15 May $2006]$.

Castillo D. 1999. Occupational safety and health in young people. In Young Workers: Varieties of Experience, Barling J, Kelloway EK (ecls). American Psychological Association: Washington, DC; 159-200.

Dehaas D. 1996. Keeping young workers sale. OHES Canada 12(3): $48-56$.

Deloy DM, Schaffer BS, Wilson MG, Vandenberg RJ. Butts MM. 2004. Creating safer workplaces: assessing the determinants and role of safety climate. Joumal of Safery' Research 35: 81-90.

Deshpande S, Basil M. 2006. Lessons from research on social marketing for mobilizing adults for positive youth development. In Mobilizing Adulls for Posilive Youth Development: Strategies for Closing the Gap Between Beliefs and Bebaniors, Clary EG, Rhodes JE (eds). Springer science + Business Media, Inc: New York; 21. $1-231$.

Donovan RJ, Henley N. 2003. Social Marketing: Principles and praclices. IP Communications: Melbourne.

Dunn KA, Runyan CW, Cohen LR, Schulman MD. 1998. Teens at work: a statewide study of jolss, hazards, and injuries. Joumal of Adolescent Health $22(1): 19-25$.

Freiman C. 2003. And the survey says: youths need more training, info. OIIES Canada 19(8): 19.

Griffin MA, Neal A. 2000 . Perceptions of safery at work: a framework for linking safety climate to safety performance, knowledge, and motivation.
Jounal of Occupational Healh Psychology 5(3): $347-358$.

Guidotti Tl, Ford L, Whecler M. 2000. The Fort McMuraty demonstration project in social marketing: theory, design, and evaluation. American foumal of Preventive Medicine 18(2): 163-169. Institute for Work \& Health (IWI). 2003. Securing a sate and healthy future: the road to injury pre vention for Ontario's young workers. Infocus 34(Fall): 1-4. http://www iwh.on.ca/archive/ pdis/ in_34a.pulf [10 May 2006].

Institute for Work \& Health (IWH). 2006a. Nonfatal injuries in young workers http://www. iwh. on.cal/media/images/LWH_youngworkers. pdf $[5$ March 2006$]$

Institute for Work \& Health (IWH), 2006b. The guide for cvaluating the effectiveness of strategies for preventing work injuries http://www. iwh.on,ca/products/evalphp [1 June 2006].

Jamieson S. 2005. Too young to dic? Camadian Forest Industries June/July: 6-8.

Jones $S$, Owen N. 2006. Using fear appeals to promote cancer screening - are we scaring the wrong people? International foumal of Nonprofit and Voluntary Sector Marketing 11: 93-103.

Kaminski M. 2001. Unintended consecuences: organizational practices and their impact on workplace safety and productivity. foumal of Occupational Ylealb Psychology' 6(2): 127-138.

Kotler P, Roberto N, Lee N. 2002. Social Matketing: Improving the Quality of life. Sage Publications: Thousand oaks, California.

Iinker D, Miller ME, Freenan KS, Burbacher $T$. 2005. Health and safety awatreness for working teens: developing a successful statewide program for educating teen workers. Family and Community lleallh 28(3): 225-238.

Loughlin C, Barling J. 2001. Young worker's work values, attitudes, and behaviors. Jom nal of occtpational and Organizational Psychology 74: 543-558.

Loughlin C, Fronc MR. 2004. Young workers' occupational safety. In The Psychology of Workplace Sajety, Barling J, Frone M (eds). American Psychological Association: Washington, DC; $107-125$.

Lyon BK. Hollcroft B. 2005. Health and safety management systems: focus on management. Occupational Hazards $67(6)$ : $45-48$. 
Marshall KP, Brown UJ, III. 2003. Target marketing in a social marketing context: gender differences in importance ratings of promoted intrinsic and cxtrinsic restricted exchange benefits of military enlistment. International fownal of Nonprofil and Folumany Sector Marketing 9(1): 69-86.

Miller TR, Wachrex GM. 1998. Costs of occupational injuries to tecnagers, United States. Imjury Prevention 4(3): 211-217.

Professional Safety. 2005. Fed Net launched effort to keep teen workers safe at work this winter. Professional Safery 50(1): 16-17.

Ross 1. 2003. Youth job safety: an employer's role. Norlbem Ontario Business 23(9): 7 .

Schulte PA, Stephenson CM, Okun AH, Palassis J, Bidclle E. 2005. Integrating occupational safety and heath information into vocational and technical education and other workforce preparation programs. American Journal of Public Healtb 95(3): $404-411$.

Smith S. 2004 . Protecting vulnerable workers. Ocupational Hazards 66(4): 25-28.

spangenberg $S$, Mikkelsen Kl. Dyreborg J, Baarts C. 2002. The consiruction of the oresund link between Denmark and Sweden: the effect of a multifaceted safety campaign. Safety science $\mathbf{4 0}$ : $457-465$.

Stelmakowich A. 2002. Young men + risk = trou risk =.:- trouble: study. OIJES Canada 18(2): 24.

Tomlinson A. 2002. New government efforts to reduce injuries. Camatian IIR Reporler 15(13): 1. $22-23$.
Van Den Broek A. 2004. Teach your children well. oHes Canada 20(4): 42-44, 46, 48 .

Vecchio-Sadus AM, Griffiths $\$$. 2004. Marketing strategies for enhancing safety culture. Safety Science 42: 601-619.

Wallace JC, Vodanovich SJ. 2003. Workplace safety performance: conscientiousness, cognitive failure and their interaction. Joumal of Occupational Heallo Psychology 8(4): $316-327$.

Weadock V. 2003. The young and the reckless? Occupational Heallh \& Sajety, 72(5): 18.

Westaby ID, Lee BC. 2003. Antecedents of injury among youth in agricutural settings: a longitudjnal examination of safety consciousness, dangerous risk taking, and safety knowledge. Joumal of Safety' Research 34: 227-240.

Westaby JD, Lowe JK. 2005, Risk-taking orientation and injury anong youth workers: examining the social intluence of supervisors, coworkers, and parents. Joumal of Afplled Psychologi, 90(5): $1027-1035$.

Workers Compensation Berard of British Columbia (WCB of BC), 2006. hattp://www demandsafety.ca [14 August 2006].

Workers Compensation Board of Nova Scotia (WCB of NS) 2005. 1http://Www considersafety.ca/ [1 March 2006].

Young I. 1998. Changing the face of safety. OHES Cancada 14(4): $24-30$.

Zakocs RC, Runyan CW, Schuman MD, Dunn KA, Evensen CT. 1998. Improving safety for teens working in the retail trade sector: opportunitics and obstacles. American Jonnal of motustrial Medicine 34: 342-350. 